\title{
Effect of Temperature Variation on Viscosity of Selected Cooking Oils
}

\author{
Sani Aliyu and Badamasi Mufidat
}

Department of physics

Usmanu Danfodiyo university Sokoto, Nigeria

\begin{abstract}
The viscosity of a liquid is a measure of that fluid's resistance to flow when acted upon by an external force such as a pressure differential or gravity. Effect of temperature variation on the viscosity of selected cooking oils were studied at five different temperatures $\left(10^{\circ} \mathrm{C}, 30^{\circ} \mathrm{C}, 50^{\circ} \mathrm{C}, 70^{\circ} \mathrm{C}\right.$ and $90^{\circ} \mathrm{C}$ ). Viscometer (cannon model 2020) was used to carry out the study. The results obtained showed that the viscosity of the three samples differs significantly while the temperature reduces the viscosity of all the oil significantly especially for groundnut oil at $30^{\circ} \mathrm{C}$. At $10^{\circ} \mathrm{C}$ coconut oil solidified, the variation in temperature and viscosity of the oil reveals that viscosity is a temperature-dependent for satisfactory mass transfer rate and low energy input during flow operation.
\end{abstract}

Keywords: Gravitational Force, Fluid, Viscosity, Viscometer.

\section{INTRODUCTION}

Viscosity is a measure of the resistance of a fluid which is being deformed by either shear stress or tensile stress. In everyday terms (and for fluids only), viscosity is "thickness" or "internal friction". Thus, water is "thin", having a lower viscosity, while honey is "thick", having a higher viscosity. Put simply, the less viscous the fluid is, the greater its ease of movement (fluidity). Viscosity describes a fluid's internal resistance to flow and may be thought of as a measure of fluid friction.

Viscosity is a general property of all fluids, which includes both liquids and gases. While the basic concept of viscosity is the same for water, milk and cooking oil [1].

This research presents the effect of temperature variation on different cooking oils the cooking used include: groundnut oil, olive oil and coconut oil. About $79 \%$ of the over 100 million tons of edible oils and fats produce worldwide annually are derived from plant sources and are referred to as vegetable oils. Vegetable oils like (Groundnut oil, olive oil and coconut oil) play important functional and sensory roles in food product and they act as carrier of fat soluble vitamin A, D, E and K. They also provide energy and essential linoleic and linolenic acids responsible for growth. Olive oil and coconut oil are one of the main ingredients used to manufacture soaps, cosmetics and pharmaceutical products. Groundnut oil is mostly used for cooking and frying of foods and snacks. In both applications, the oil is subjected to elevated temperature in the range of $35^{\circ} \mathrm{C}$ to $180^{\circ} \mathrm{C}$. The Optimum design of heating and cooling systems for cooking and frying, and the fundamental understanding of cooking and frying process required that the thermo-physical properties of groundnut oil, olive oil and coconut oil are known. two of the important thermo-physical properties are viscosity and specific heat [2].

Physical property that relates to resistance to flow of fluid is called viscosity. It occurs when molecules of fluid exert friction force on each other as layer of fluid tend to slide against each other. Selection of fluid handling equipment and sizing require adequate knowledge of viscosity in order to determine the power needed to facilitate loading and discharging of fluid materials. In diesel engines, viscosity is needed to estimate atomization rate and whole engine efficiency [3]. 
International Journal of Advances in Scientific Research and Engineering (ijasre), Vol 6 (4), April -2020

\section{MATERIALS}

The materials used in this research include; Viscometer 2020, Multipurpose digital thermometer, 50ml beaker, stop watch, heating mantle, Olive oil, Ground nut oil, Coconut oil.

\section{METHODOLOGY}

\subsection{Sample collection}

The sample were obtained from Sokoto central market, Sokoto Nigeria, labelled as sample A, B and C representing olive oil, groundnut oil and coconut oil respectively.

\subsection{Sample preparation}

$50 \mathrm{ml}$ of sample A was taken into the beaker and kept into the refrigerator until it temperature is becomes lower than $10^{\circ} \mathrm{C}$, it was then brought out. The spindle of the viscometer was also immersed into oil sample and allowed to rotate for 60rmp in $120 \mathrm{~s}$ in order to allowed the viscometer reading to be stable, the viscosity of the sample at $10^{\circ} \mathrm{C}$ display on the displaying screen was recorded.

Sample A was heated with heating mantle that has temperature control to $30^{\circ} \mathrm{C}$ and the viscometer spindle was allowed to rotate for $60 \mathrm{rpm}$ in $120 \mathrm{~s}$, and viscometer reading was recorded. The heating mantle was adjusted to $50^{\circ} \mathrm{C}$ at the same time the viscometer reading was recorded, also the heating mantle was adjusted to $70^{\circ} \mathrm{C}$ and the viscometer reading was also recorded and at $90^{\circ} \mathrm{C}$ the viscometer reading was also recorded. This process was repeated for sample $\mathrm{B}$ and $\mathrm{C}$ and result were recorded. This method used was the method adopted by [4].

\section{RESULTS}

The result obtained from experimental measurement of viscosity of three cooking oils at temperature of $10^{\circ} \mathrm{C}, 30^{\circ} \mathrm{C}$, $50^{\circ} \mathrm{C}, 70^{\circ} \mathrm{C}$ and $90^{\circ} \mathrm{C}$ are shown in table 1

Table 1: Effect of temperature on the viscosity of olive oil, groundnut oil and coconut oil

\begin{tabular}{|c|c|c|c|c|c|}
\hline \multirow[t]{2}{*}{ Viscosity $(C p)$} & \multicolumn{3}{|c|}{ Temperature $\left({ }^{\circ} \mathrm{C}\right)$} & \multirow[b]{2}{*}{70} & \multirow[b]{2}{*}{90} \\
\hline & 10 & 30 & 50 & & \\
\hline Olive oil & 47.5 & 24.1 & 12.8 & 9.4 & 6.9 \\
\hline Groundnut oil & 71.3 & 24.4 & 15.6 & 10.1 & 7.5 \\
\hline Coconut oil & 0.0 & 20.9 & 12.5 & 8.8 & 5.9 \\
\hline
\end{tabular}




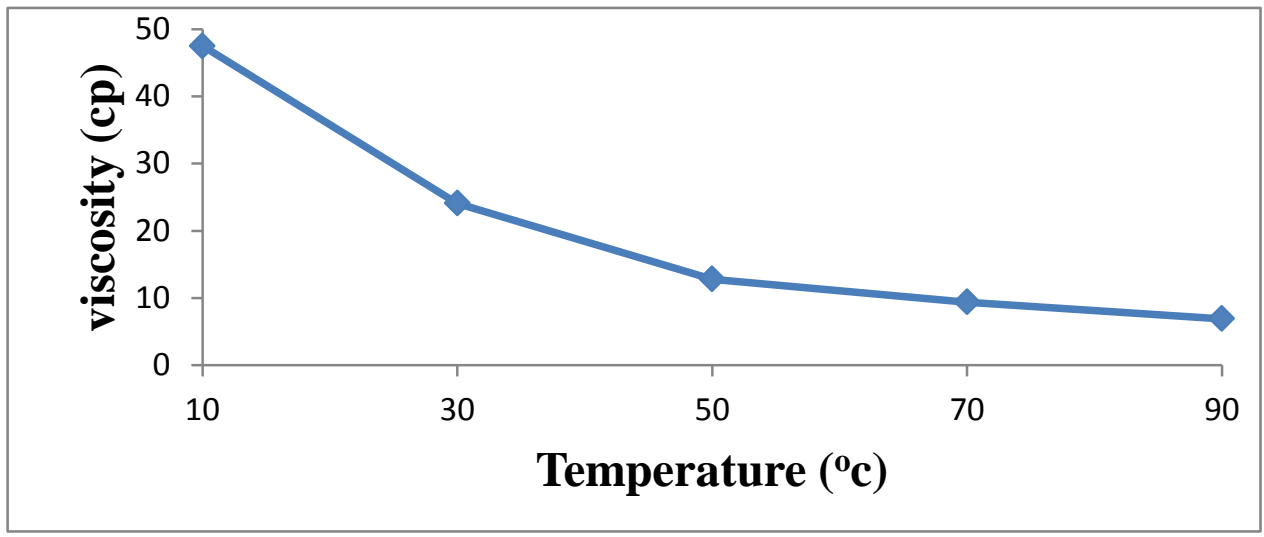

Figure 1: Viscosity of olive oil Vs Temperature

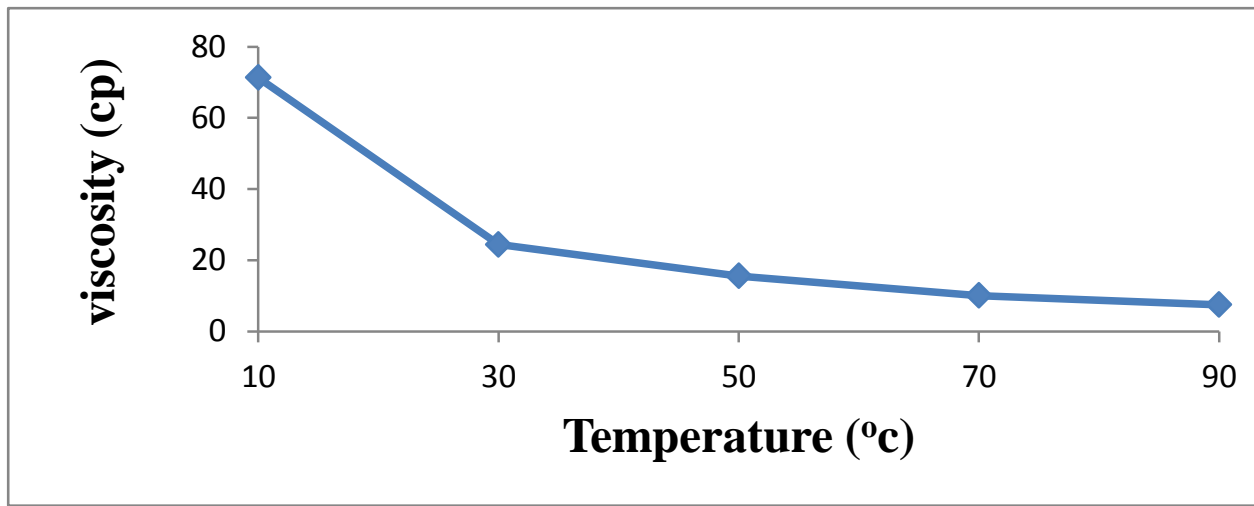

Figure 2: Viscosity of Groundnut oil Vs Temperature

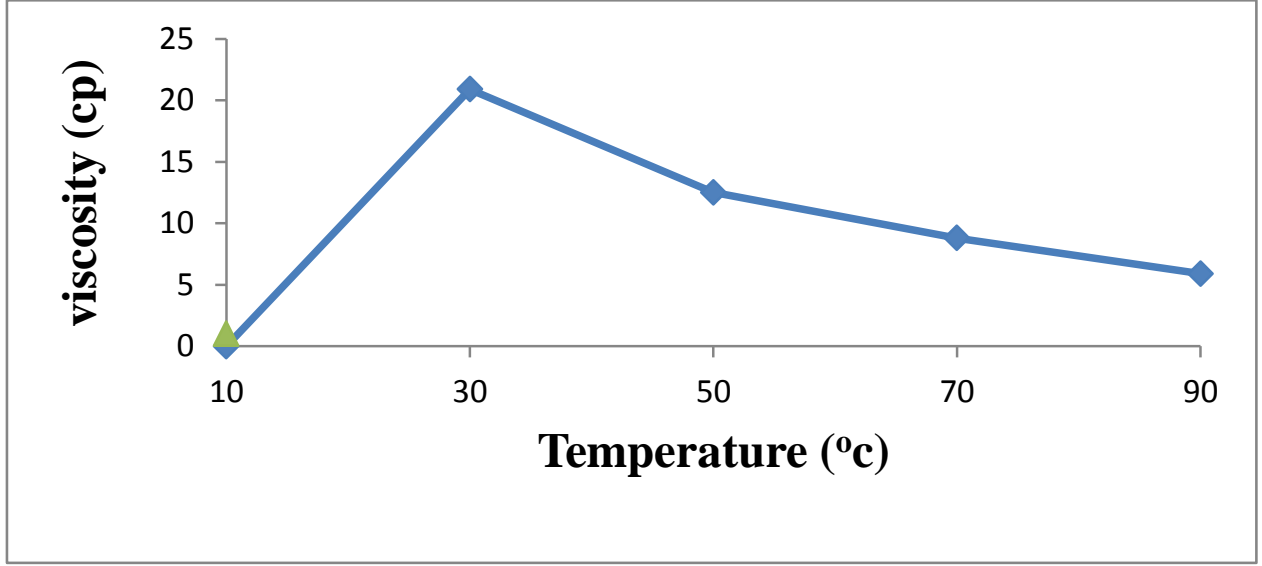

Figure 3: Viscosity of Coconut oil Vs Temperature

\section{DISCUSSION}

Table 1 shows the effect of temperature on viscosity of the selected cooking oils at different temperatures. The results shown in figure 1 revealed that viscosity of olive oil decreases with increase temperature. Similarly, figure 2 indicated that the viscosity of groundnut oil decrease with increase in temperature, similarly figure 3 shows the effect of temperature on viscosity of coconut oil, from the figure it is obvious that coconut oil solidified at $10^{\circ} \mathrm{c}$. Figure 4 shows the variation of viscosities of olive oil, groundnut oil and coconut oil with temperature. Groundnut oil has the highest viscosity value of $71.3 \mathrm{cp}$ at the minimum temperature, while coconut oil has least viscosity value of $0 \mathrm{cp}$. Groundnut oil has the highest viscosity value of $7.5 \mathrm{cp}$ and coconut oil has least value of $5.9 \mathrm{cp}$ at maximum temperature, which means that olive oil has viscosity values that are in between groundnut oil and coconut oil. 
This result may be attributed to the increase of the mean temperature for temperature dependent viscosity compare to constant viscosity. Due to the higher mean temperature, the temperature dependent viscosity is lower compare to the case of constant viscosity, which reduces the flow resistance and strengthen the effect of secondary flow on heat transfer enhancement. There is a significant different between the oil viscosities of the three varieties.

\section{CONCLUSION}

A research was carried out on the effect of temperature variation on viscosity of olive oil, Groundnut oil and coconut oil using viscometer (cannon model 2020) with spindle revolution of 60rpm in 120 s.It can be concluded from this study that temperature affects the viscosity of oils at temperatures between $10-90^{\circ} \mathrm{C}$ with viscosity decreasing. Because the viscosity decreases with increasing temperature, the viscosity of all samples are low at higher temperature. This confirmed that the viscosity of these samples were temperature dependent, as such the frictional factor decreases as the viscosity decreases.

\section{REFERENCES}

1. Santos, J. C. O., Santos, I. M. G. and Souza, A. G. (2005). Effect of heating and cooling on theological parameters of edible vegetable oils. Journal of Food Engineering, Vol 67(4): PP. 401-405.

2. Telis, V. R. N. Telis-Romero, J.; Mazzotti, H. B.; Gabas, A. L. (2007) Viscosity of aqueous carbohydrate solutions at different temperatures and concentrations. International Journal of Food Properties. Vol. 10, 185-195.

3. Knothe G. and Steidley K. R. (2005). Kinematic viscosity of biodiesel fuel components and related compounds. Influence of compound structure and comparison to petro-diesel fuel components. Vol. 84: PP. 1059-1065.

4. Steffe, J. F. (1996). Introduction to rheology. In: Rheological Methods in Food Process Engineering. Freeman Press, East Lansing, USA. 